\title{
Digitalisation of an Analogue Weighing Scale Using Microcontroller
}

\author{
${ }^{1}$ S. A. Fagbemi, ${ }^{2}$ M. Momoh, ${ }^{2}$ I. G. Saidu, ${ }^{2}$ D. O. Akpootu, ${ }^{2}$ S. B. Sharafa and \\ ${ }^{1}$ M. J. Abdulsalami \\ ${ }^{I}$ M. Sc. Student, Department of Physics, Usmanu Danfodiyo University, Sokoto, Nigeria. \\ ${ }^{2}$ Department of Physics, Usmanu Danfodiyo University, Sokoto, Nigeria.
}

\begin{abstract}
Most of the weighing machines available currently are the analogue types. Analogue weighing machines are often not very accurate and convenient to read. In this research, analogue weighing machine was obtained from the market and converted to a digital type. To do this, the extension of the spring in the analogue weighing machine was first converted into voltage using a simple voltage divider circuit. The output of the voltage divider (transducer) was then fed into a microcontroller that converts the analogue voltage into a corresponding digital value using the internal ADC embedded in a microcontroller. The microcontroller was programmed to display the mass and the corresponding weight of the measured weight simultaneously on a Liquid Crystal Display(LCD device). The readings of the digital weighing machine produced were used to compare that of a standard weighing type. The result showed that there was a mean deviation of $1.44 \mathrm{Kg}$ between the readings of the modified scale and the analogue type which served as the control. A simple product moment correlation coefficient was used to compare the two readings and the result obtained indicated that there was a near perfect correlation (0.9998) between the readings of the two scales.
\end{abstract}

Keywords: Digitisation, analogue, weighing scale, microcontroller, $A D C, L C D$.

\section{Introduction}

Measurement techniques have been of immense importance ever since the start of human civilization, when measurements were first needed to regulate the transfer of goods in barter trade to ensure that exchanges was fair. The industrial revolution during the nineteenth century brought about a rapid development of new instruments and measurement techniques to satisfy the needs of industrialized production techniques (Alan, 2001).This, in turn, has required a parallel growth in new instruments and measurement techniques (Alan, 2001).Nowadays, the demand for digital weighing machine is increasing day by day in most business enterprises because measuring the weight with digital weighing machine is user friendly with variety of various applications (Sartish and Vanaraj, 2012). Hence, the trends to use digital weighing machine instead of classical weighing system is adopted mostly in the world and so the demand increases to design variety of advanced digital weighing machine at competitive level (Sartish and Vanaraj, 2012).Several digital weighing scale designs have been presented in quite a number of publications; these designs exhibit different unique features. For instance, Jorge (2012 a) did three different projects with different scales. He started out with the Fagor BB-90 scale, a cheap and simple scale with LCD screen. The goal of his project was to store the data on an SD card and further add more advanced features to the scale. He did so by removing the original LCD screen and then added his own LCD screen and a microcontroller (LPC2103) which he could easily control. The microcontroller fetched data from the SD card and did multiple calculations before outputting it on the LCD screen. The new features were time and date, increase or decrease in weight, and multi-user support. Jorge (2012 b) further improved the scale to give it Bluetooth connectivity. The scale communicated with his Android mobile phone via a Bluetooth link. He used the Android application Smart Weight Chart to show the data as a graph. His second work was similar to the first one but with a different scale. Thirdly, he manipulated the Beurer BG 16 scale which measures weight, percentage of fat, percentage of water, and percentage of muscle (Jorge, 2012b). He made the same modifications as with the other scales.Though the scale was very sophisticated, it was however expensive and not affordable by most people.

The need for people to regularly check their weight cannot be overemphasized. Today, the number of patients with obesity is growing at an alarming rate,the risk ofheart diseases and stroke problems are also on the increase. Overweight and obese individuals are at increased risk for many diseases and health conditions, including the high blood pressure, high LDL cholesterol and low HDL cholesterol, diabetes, plaque in arteries of heart, heart Stroke, gall bladder infection, degenerative joint disease, respiratory problems, and breast cancer.Asthese diseases are weight related, bathroom scales become necessary asthose who do not have a bathroom scale at home often do not bother to check their weight and this can be harmful to their health. Most of the weighing machines available are analoguetypes. Analogueweighing machines, though relatively cheap and do not require power supply are however associated with the problems of zero error, calibration, 
inaccurate results etc. Furthermore, the few digital weighing machines available in the market are very expensive and not affordable by most people, hence, the need for designing and constructing a digital weighing scale., the demand for digital weighing machine is increasing day by day in most business enterprises because measuring the weight with digital weighing machine is user friendly with variety of various applications (Sartish and Vanaraj, 2012).

\section{Design}

\section{Methodology}

Broadly, the design can be categorized into two parts; the mechanical part and the electrical part. The mechanical section essentially is the modification of the system to enable the conversion of the mechanical compression of the spring into corresponding electrical quantity while the electrical part is concerned with the digitalization of the resultant analoguevoltage.The block diagram of Figure 1 illustrates the main sections of the weighing machine.

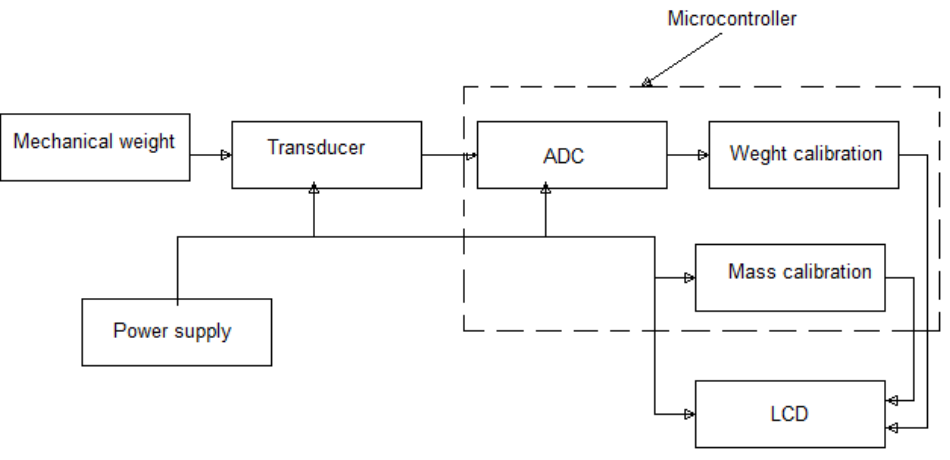

Figure 1: Block diagram of the weighing machine.

The block diagram comprises of the analogueweighing machine that is to be digitalised. A transducer comprising of a potentiometer and voltage sourcewas used to convert the mechanical energy as sensed by the spring into electrical signal. An ADC located in a microcontroller is then programmed to generate a digital signal representation of the analoguequantity. The microcontroller was then programmed to produce the measured weight on one hand and the mass on the other. Both the mass and weight are then displayed side by side on an LCD. For the circuits to operate a power supply is provided and fed to all the sections requiring it.

\section{- The scale modification}

The cover of the bath scale is removedto reveal a large dial, a rack and pinion arrangement that turns the dial, a spring and a lever as shown in Plate1.

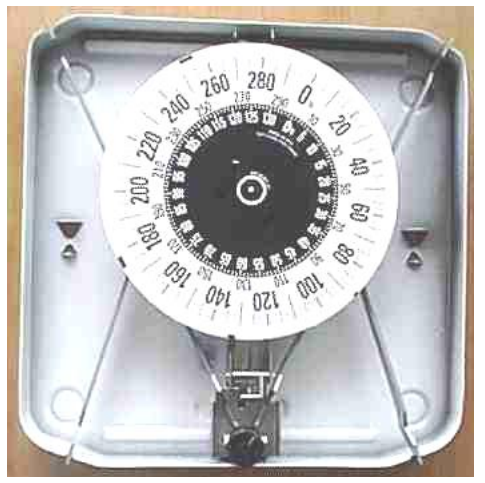

Plate 1: The internal part of the analogue scale

In the plate, a long lever, fixed at the left end, has weight applied to it very close to the fixed end. At the right end of the lever the weight is significantly reduced by a ratio determined by the relative difference between the length from the left end to the weight and the distance from the left end to the right end. The spring plate moves up and down andthis motion is translated by a pivot into side-to-side motion. This motion is sent to a rack and pinion arrangement. The rack and pinion arrangement was carefully removed and the arm of a potentiometer attached as illustrated in figure 2 . 


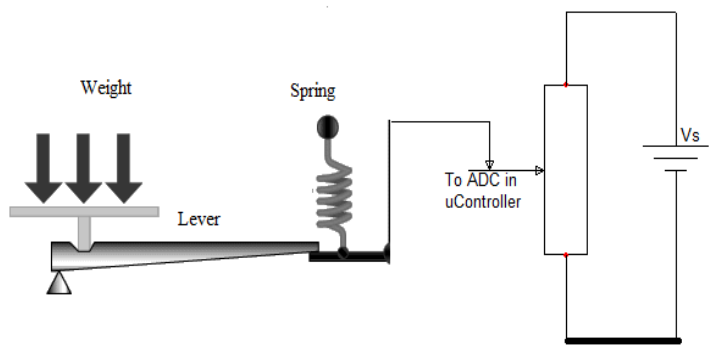

Figure 2: The system after modification

The arm of the lever is attached to the moving arm of the potentiometer. A mass placed on the weighing platform causes the lever to move proportional to the weight. This movement is used to appropriately extend the attached spring. The spring movement is used to vary the potentiometer in accordance with the weight of the mass. Consequently, the measured weight is converted to electrical quantity using the potentiometer which is a transducer. The output of the potentiometer (figure 3) which is an analoguevoltage is then fed to the ADC terminal of the microcontroller for conversion into digital equivalent.

\section{- AnalogueSignal Unit}

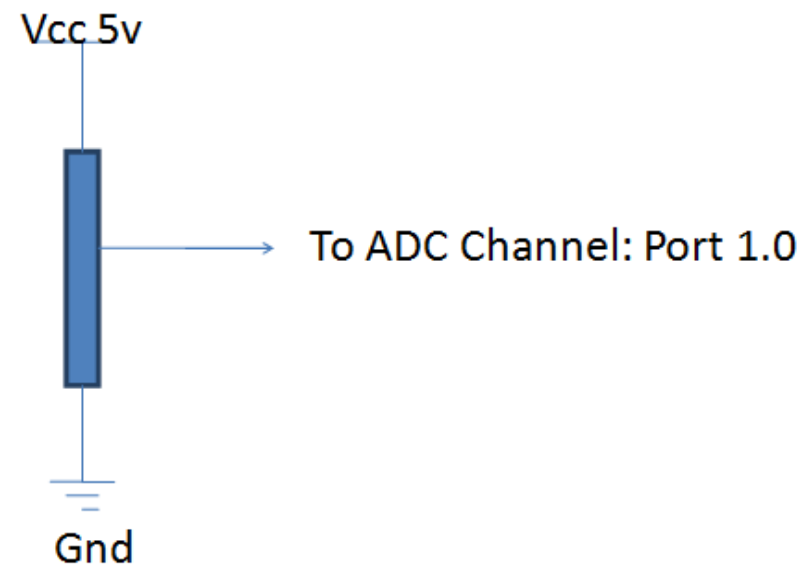

Figure 3: Conversion of extension to electrical quantity using potentiometer

The analoguesignal unit consists of a variable resistor; one end of the variable resistor is pulled up to $\mathrm{V}_{\mathrm{cc}}$ and the other end to ground. The third end which is the centre terminal is connected to the ADC channel of the microcontroller that corresponds to Port 40 of the microcontroller. The centre tap forms a voltage divider network.

From voltage divider law, the voltage across the centre arm and ground (V) is given as;

$\mathrm{V}=\left(\mathrm{V}_{\mathrm{s}} \mathrm{R}_{2}\right) /\left(\mathrm{R}_{1}+\mathrm{R}_{2}\right)$

Where

Vs $=$ Voltage across the two ends of the potentiometer

$\mathrm{R}_{1}=$ Resistance at the upper arm of the potentiometer

and $\mathrm{R}_{2}=$ Resistance between the centre arm and the ground

The variable resistor used here is of the value $50 \mathrm{k} \Omega$. Now if current is held constant, "V" will be directly proportional to " $R$ " i.e. when resistance is reduced, voltage will increase and vice versa.

\section{- ADC Design}

The output of the potentiometer transducer was connected to the pin 40 of the microcontroller. With converters, the precision is basically governed by the number of bits in the digital output usually called the resolution. In this research work, an 8 -bit converter produced $2^{8}=256$ possible digital values, it works over a range $0-5 \mathrm{~V}$. A change of one bit in the output corresponds to a change of $(5 \mathrm{~V}) / 256 \approx 19.5 \mathrm{mV}$ in its input. This is called the $L S B$ for least significant bit and is another way of defining the resolution. The ADC itself has a resolution of 8 bits and the system has a resolution of $\mathrm{LSB}=19.5 \mathrm{mV}$.

The internal ADC of the microcontroller is 8-channel with the connections at pins 33 to pin 40. This terminals apart from serving as port $\mathrm{A}$ with bits $\mathrm{A}_{\mathrm{o}}$ to $\mathrm{A}_{7}$ also serves as the $\mathrm{ADC}$ terminal, from $\mathrm{ADC}_{\mathrm{o}}$ to $\mathrm{ADC}_{7}$ where the lowest bit is 40 and the highest bit is bit $\mathrm{PA}_{7}$ (pin 33).In this project, only one sensor (output of the potentiometer) is connected to the least significant bit of the port A (pin 40). The microcontroller ADC employs 10 bits for successive approximation analogueto digital conversion. The input are multiplexed internally and converted to digital signals as configured. Internally the signal is amplified by a programmable amplifier before 
conversion. Before conversion a sample and hold circuit is internally used to hold the data while it is being converted. This ensures that the converted voltage remains constant during the conversion process (Ismaila and Momoh, 2013).

\section{- Power supply unit}

A necessity for all electronics circuits is a power supply. Power supplies must be properly rated to ensure proper working condition of the circuit. For this project the sections requiring voltage sources are the microcontroller, transducer and the LCD circuits. The voltage specification of the microcontroller and that of the LCD in their data sheet is 5 Volts. Based on the above a voltage source of $5 \mathrm{~V}$ was also chosen for the transducer to reduce circuit complexity. For portability, a battery was used as supply. To ensure stable voltage, a $9 \mathrm{~V}$ battery was chosen then stabilised to $5 \mathrm{~V}$ using a Zener diode. With this arrangement the $5 \mathrm{~V}$ supply is ensured for a longer duration. The power supply circuit is made up of a $9 \mathrm{Vdc}$ battery, capacitor $(1000 \mathrm{uf} / 25 \mathrm{v})$, a $100 \Omega$ resistor and a $5.1 \mathrm{Vdc}$ Zener diode.

The dc voltage is fed through the $100 \Omega$ resistor connected in series with the cathode of the Zener diode forming a resistive diode voltage divider network. The output which is a $5 \mathrm{Vdc}$ is in turn fed to the microcontroller which is its required voltage.

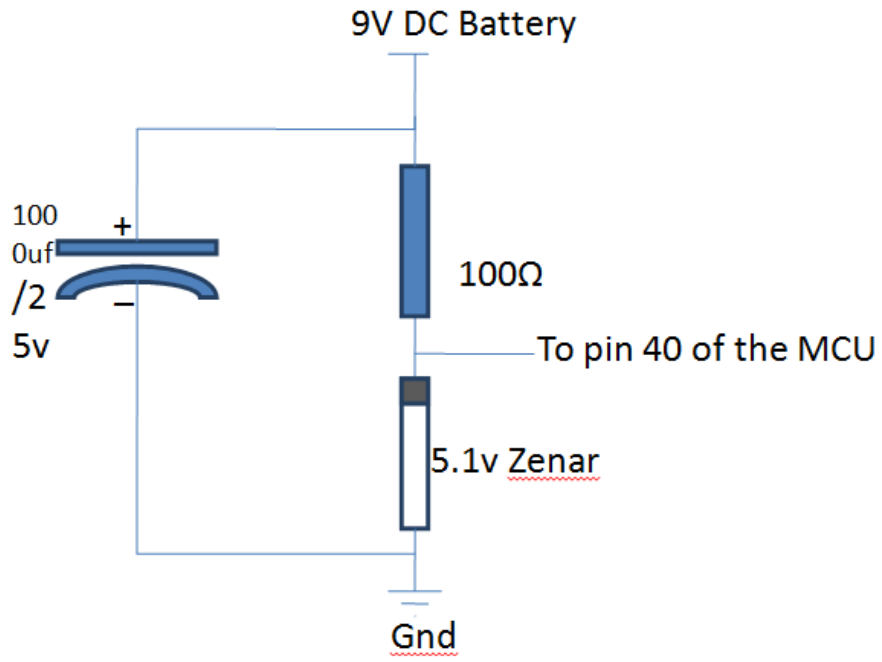

Figure 4: Power supply circuit.

\section{- The LCD Unit Design}

The microcontroller was programmed to interface the output of the ADC with an LCD unit. The LCD used is shown in Figure 5 with its pin configurations.

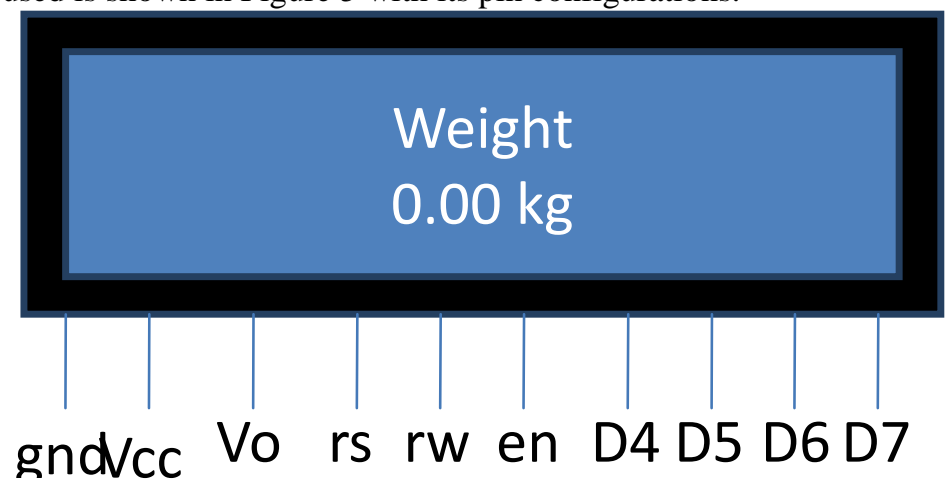

Figure 5: The LCD package with its pins configuration.

The display unit is made up of a 16 character by two rows LCD (liquid crystal display). The gnd terminal is connected to ground of the $5 \mathrm{~V}$ supply while $\mathrm{V}_{\mathrm{cc}}$ is connected to the positive terminal of the $5 \mathrm{Vdc}$ supply. $\mathrm{V}_{\mathrm{o}}$ is connected through a $2 \mathrm{k} \Omega$ resistor to $\mathrm{V}_{\mathrm{cc}}$ for setting the contrast while the corresponding rs, rw, en, D4, D5, D6 and D7 are connected to the microcontroller port 2. The 8 bit output of the ADC is sent to the LCD by breaking it into two halves of lower nibble and upper nibble. The technique allows 8 bit data to be sent via a four wire bus therefore minimising the number of wires used. The eventual complete circuit diagram is in figure 6. 


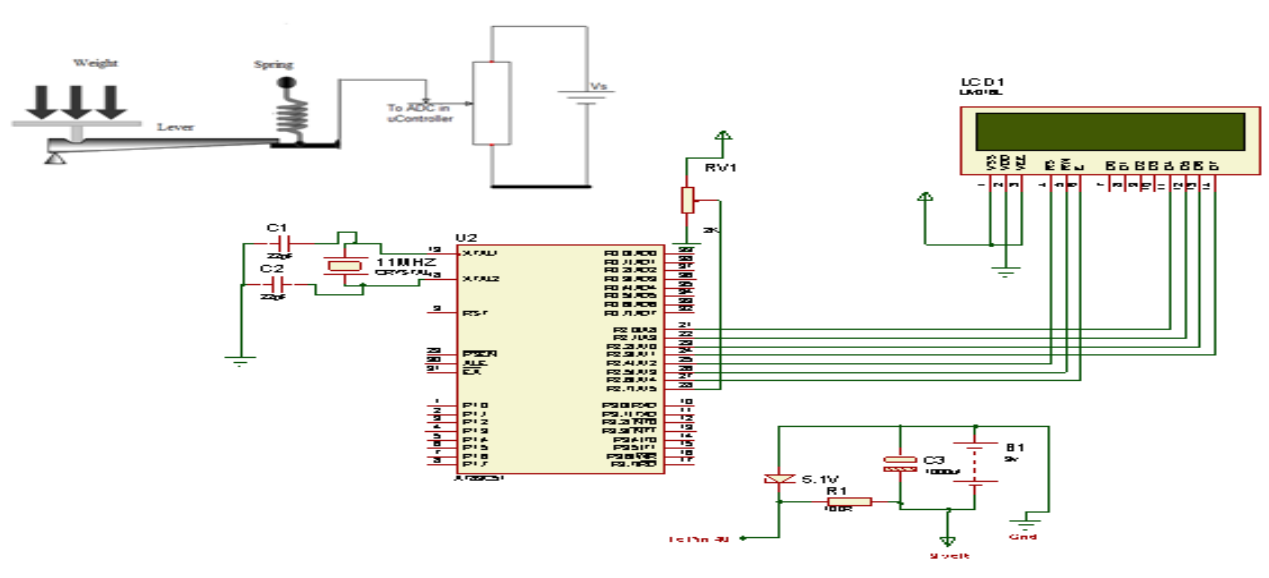

\section{- Software Development}

Figure 6: The circuit diagram of the system

The program was written, compiled and loaded into the microcontroller using STC90RC51 programmer. The flow chart in Figure 6 gives brief description of the software development. The programming language used is the $\mathrm{C}$ language. The $\mathrm{C}$ language incorporates a number of functionalities which makes it very versatile. The inclusion of a wide range of header files for various microcontrollers makes $\mathrm{C}$ language most suitable for programming embedded control systems. $\mathrm{C}$ language also allows the embedding of assembly language within it. Delay routines in $\mathrm{C}$ are mostly written in assembly language, embedded within the $\mathrm{C}$ language thereby making it possible to still use $\mathrm{C}$ to handle applications requiring real-time speed. Figure 7 illustrates the conversion flow chart.

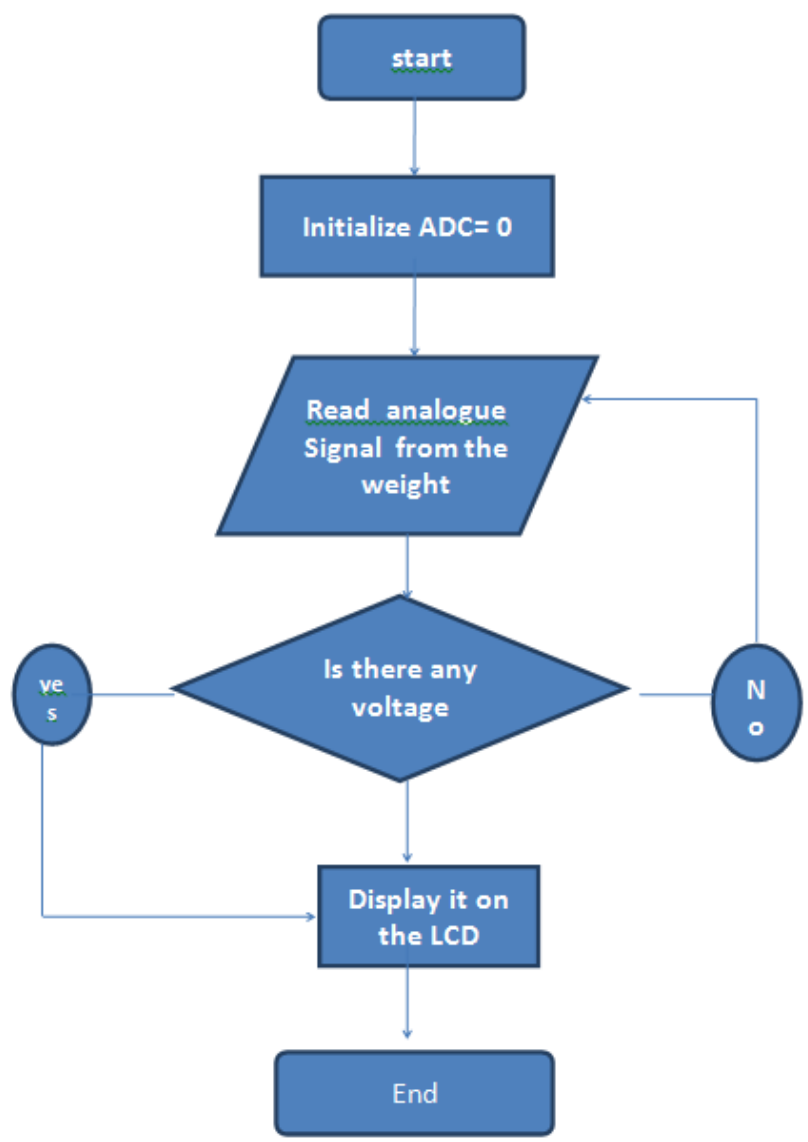

Figure 7: System flow Chart.

At the start, when the device is switched on, the microcontroller initialises its internal ADC to zero to avoid error. The value of the voltage from the potentiometer is read by the microcontroller. The value is converted to digital form by the ADC converter. This value is used to compare the initial value on the ADC. If there is difference, the value is displayed on the LCD, otherwise the microcontroller goes back to monitor if there is 
change in the value of the potentionmeter. Changes in the potentiometer output is as a result of load placed on the weighing machine.

\section{Construction}

Each component was first tested to acertain there working conditions. The circuit was pretested temporarily on a bread board then permernently soldered on a vero board. A 40pin socket was first soldered to the board then the microcontroller IC was plugged in. This allows for easy maintainability as they could easily be replaced. Additionally the IC socket ensures that the microcontroller which is the most expensive is not damaged during soldering. The LCD was transferred to the front panel. The analogue display unit was carefully removed and replaced by the digital LCD. A preset potentiometer was also provided to set the constructed weighing machine value to zero before use.

For the purpose of safeguarding the life span of the battery a control switch is provided at the front of the panel so that power can be switched off when not in use.

\section{TESTING}

\section{- $\quad$ Range Test}

The scale was tested to determine the range of values for which the scale can be used. The lower limit was determined by taking the scale reading on no load while the upper limit of the scale was determined by gradually loading the scale using a vice as the source of load. The vice was gradually tightened to load the scale. This process was continued until the scale reading remained constant and did not respond to further tightening of the screw. This reading was recorded as the upper limit.Care was taken not to over tight the screw as this could affect the elastic limit of the spring.

\section{- Accuracy Test}

For the accuracy test a standard weighing machine was obtained and its readings used to compare that of the digitised scale. The two scales were placed side by side and used to take the weights of some selected students and teachers of a secondary school (Sani Dingyadi Unity Secondary School, Farfaru, Sokoto). At each instance the weight of each person was measured with the analogue scale then with the digital scale.

The results of the measurements were then tabulated. The difference between the analogue scale measurement $\left(\mathrm{W}_{\mathrm{a}}\right)$ and that of the digital type $\left(\mathrm{W}_{\mathrm{d}}\right)$ was also calculated.

. The mean difference $\left(\mathrm{W}_{\mathrm{m}}\right)$ was evaluated as;

$\mathrm{W}_{\mathrm{m}}=\frac{\Sigma(W a-W d)}{N}$

Where $\mathrm{N}=$ number of measurements taken.

A simple product moment correlation coefficient was used to establish the relationship between the two readings. The product moment correlation coefficient was calculated using equation (2)

$r=\frac{C_{A B}}{\sqrt{C_{A A} C_{B B}}}$

Where;

$\mathrm{A}=$ readings obtained from modified weighing scale

$\mathrm{B}=$ readings obtained from the analogue weighing scale

$C_{A B}=\sum A B-n \bar{A} \bar{B}$

$\mathrm{C}_{\mathrm{AA}}=\sum A^{2}-n \bar{A}^{2}$

$C_{B B}=\sum B^{2}-n \bar{B}^{2}$ and

$\mathrm{n}$ is the number of values $=9$

\section{Results}

\section{The result of the construction}

The internal modification and electrical circuit diagrams are captured in plate 2 while plate 3 shows the final construction of the modified scale. 


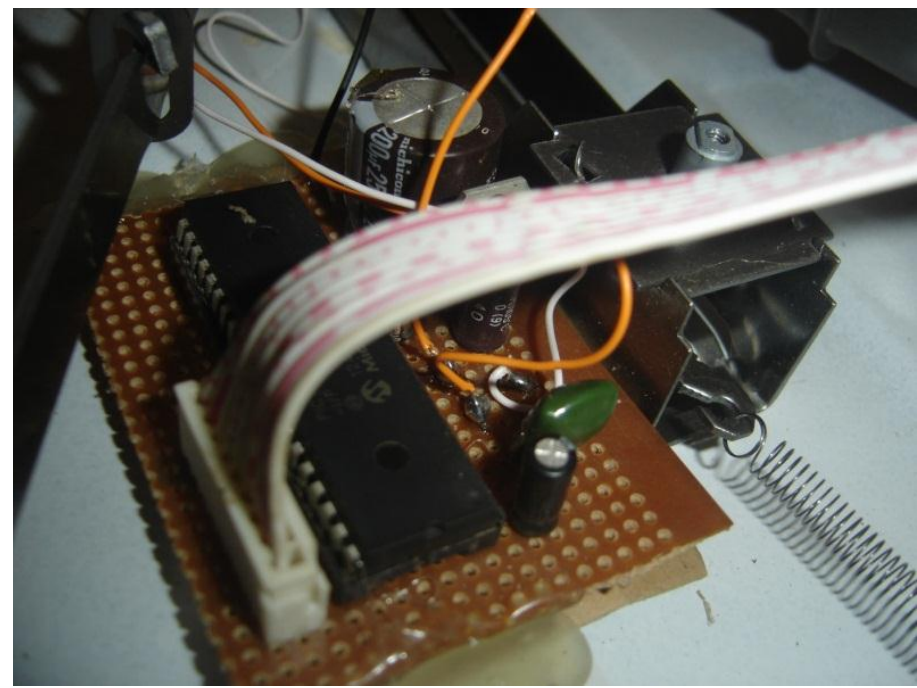

Plate 2: The constructed circuit diagram

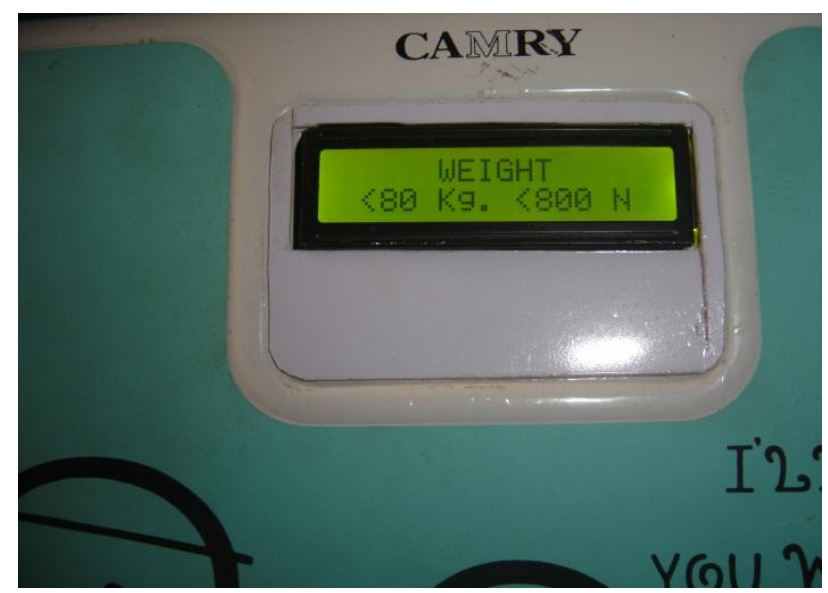

Plate 3: The complete project

- $\quad$ Range Test Result

Table 1: The result of the range

\begin{tabular}{|c|c|}
\hline Minimum scale value & Maximum scale value \\
\hline $0 \mathrm{Kg} / 0 \mathrm{~N}$ & $118 \mathrm{Kg} / 1180 \mathrm{~N}$ \\
\hline
\end{tabular}

\section{- Accuracy Test Result}

The result of the accuracy test compares the measurements of an analogue weighing machine to that of the modified digital machine. The result is in table 2 and plotted using excel Microsoft package in figure 8 . For the purpose of comparison the value of analogue weight was repeated with one serving as the control.

Table 2: The result of the accuracy test

\begin{tabular}{|c|c|c|c|}
\hline $\begin{array}{c}\text { Control value } \\
(\mathbf{K g})\end{array}$ & $\begin{array}{c}\text { Analogue weighing scale } \\
\left.\left(\mathbf{W}_{\mathbf{a}}\right) \mathbf{( K g}\right)\end{array}$ & $\begin{array}{c}\text { Modified digital scale value } \\
\left.\left(\mathbf{W}_{\mathbf{d}}\right) \mathbf{( K g}\right)\end{array}$ & $\begin{array}{c}\text { Difference(Kg) } \\
\left(\mathbf{W}_{\mathbf{a}}-\mathbf{W}_{\mathbf{d}}\right)\end{array}$ \\
\hline 32.00 & 32.00 & 30.60 & 2.60 \\
\hline 36.40 & 36.40 & 35.00 & 1.40 \\
\hline 46.40 & 46.40 & 45.30 & 1.10 \\
\hline 56.20 & 56.20 & 55.40 & 0.80 \\
\hline 65.00 & 65.00 & 64.30 & 0.70 \\
\hline 71.40 & 71.40 & 69.50 & 1.9 \\
\hline 75.60 & 75.60 & 74.40 & 1.2 \\
\hline 79.60 & 79.60 & 78.60 & 1.0 \\
\hline 86.10 & 86.10 & 84.50 & 1.6 \\
\hline
\end{tabular}

Mean difference $\mathrm{W}_{\mathrm{m}}=1.144$ 
readings of analogue scale $(\mathrm{Kg})$

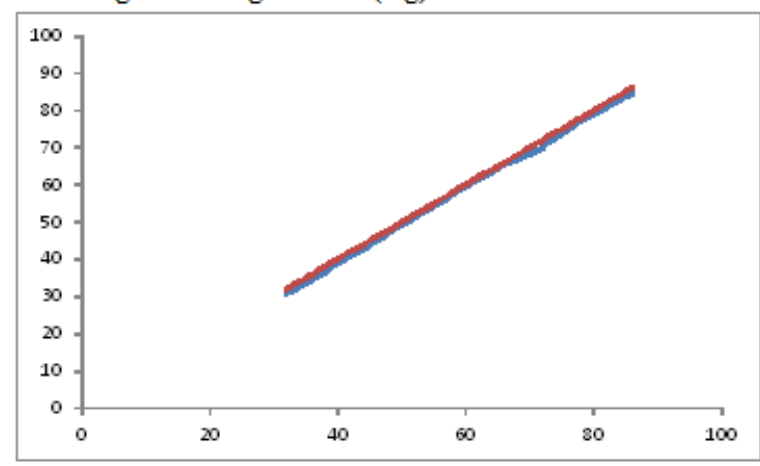

Readings of modified scale $(\mathrm{Kg})$

Figure 8: Graph of the analogue values against digital values

- Correlation coefficient result

The table for the product moment correlation coefficient is shown in table 3.

Table 3: The table showing the product moment correlation coefficient of the two readings

\begin{tabular}{|c|c|c|c|c|}
\hline $\mathbf{A}$ & $\mathbf{B}$ & $\mathbf{A}^{\mathbf{2}}$ & $\mathbf{B}^{\mathbf{2}}$ & $\mathbf{A B}$ \\
\hline 30.60 & 32.00 & 936.36 & 1024.00 & 979.20 \\
\hline 35.00 & 36.40 & 1225.00 & 1324.96 & 1274.00 \\
\hline 45.00 & 46.40 & 2025.00 & 2152.96 & 2088.00 \\
\hline 55.40 & 56.20 & 3069.16 & 3158.44 & 3113.48 \\
\hline 64.30 & 65.00 & 4134.49 & 4225.00 & 4179.50 \\
\hline 69.50 & 71.40 & 4830.25 & 5097.96 & 4962.30 \\
\hline 74.40 & 75.60 & 5535.36 & 5715.36 & 5624.64 \\
\hline 78.60 & 79.60 & 6177.96 & 6336.16 & 6256.56 \\
\hline 84.50 & 86.10 & 7140.25 & 7413.21 & 7275.45 \\
\hline 537.30 & 548.70 & 35073.83 & 36448.05 & 35753.13 \\
\hline
\end{tabular}

Table 4: Result of the product moment correlation coefficient

\begin{tabular}{l|r}
$\mathrm{r}$ & 0.9998 \\
\hline
\end{tabular}

\section{- Range}

\section{Discussion}

A test was conducted to find the range or span for which is the dynamic range of stimuli which may be converted by a sensor. It represents the highest possible input value that can be applied to the sensor without causing an unacceptably large inaccuracy (Lund et al., 2008). The range was found to be $0-118 \mathrm{Kg}$. The upper limit value of $118 \mathrm{Kg}$ is $2 \mathrm{Kg}$ short of the expected value of $120 \mathrm{Kg}$ with the possible reason for the error being ADC conversion error that arises during conversion of mechanical extension in the spring to electrical quantity. The sensor in this research is the spring in the weighing scale which senses the applied force and converts it to an extension that is linearly proportional to the applied load. The constant of proportionality is the spring constant (Hooke's law). The upper limit value corresponds to the maximum compression achievable on the spring.

\section{- Accuracy}

In the test to determine the accuracy of the device it is seen that all the differences are positive. This is why the graph of the digital scale measurement is seen to shift downwards from that of the analogue type as shown in figure 8 . This means that in all the cases the value of the measurement by the modified scale is always greater than that by the analogue type. The highest difference recorded was $2.6 \mathrm{Kg}$ while the lowest value was $0.8 \mathrm{Kg}$. The mean of the differences was found to be $1.144 \mathrm{Kg}$ and this implies that if 1.44 is added to all measurements of the digital scale a more accurate result would be obtained. In essence $\mathrm{W}_{\mathrm{d}}=\mathrm{W}_{\mathrm{a}}+1.44$.

The product moment correlation coefficient is 0.9998 as in table 4 which shows that there is a near perfect correlation relationship between the results of the weighing scales. This connotes that the readings from the modified scale is reliable. 


\section{- CONCLUSION}

In this research a system has been designed that could be of immense use in the health care sector. The weight measuring device is found to be working satisfactorily with high accuracy. The system is compact and linear. The modified weighing machine should prove handy in homes, offices and to healthcare service providers in monitoring weights. The modified weighing machine though has small error; it is quite cheap and affordable to the common man. It is however suggested that loading of the weighing machine should be maintained within the recommended range to avoid spring deformation.

\section{References}

[1] Alan, S. M. (2001). Measurement and Instrumentation Principles. Oxford, Auckland, Boston,Johannesburg, Melbourne and New Delhi: Butterworth Heinemann.

[2] Ismaila, S. and Momoh, M. (2011): Temperature sensing and GSM messaging of patient. Paper presented at Solar Energy Society of Nigeria Annual Conference. Sokoto Energy Research Center: Energy Society of Nigeria $16^{\text {th }}$ November, 2011.

[3] Jorge, P. (2012a). An Open source bathroom scale with bluetooth communication to Android Smart Phones.

[4] Jorge, P. (2012b). Digital bathroom scale which logs weight and dataon SD Card. Retrieved from www.code.google.com/p/casainhoprojects/

[5] Lund, R., Manjrekar, M., Steimer, P., and Lipo, T. (2008); Control strategy for ahybrid seven-level inverter, in Proc. European Power Electronics Conf.(EPE'), Lausanne, Switzerland.

[6] Sartish, M. K. \& Vanaraj, B. V. (2012). Design and implementation of high precision advanced weighing machine with TFT panel. Journal of Engineering Research and Technology. 